\title{
A comparison of immunomagnetic separation, direct culture and polymerase chain reaction for the detection of verocytotoxin-producing Escherichia coli 0157 in human faeces
}

\author{
M. D. CUBBON, J. E. COIA, MARY F. HANSON and FIONA M. THOMSON-CARTER*
}

Department of Clinical Microbiology, Western General Hospital NHS Trust, Edinburgh EH4 2NP and ${ }^{*} E$. coli O157 Reference Laboratory, Department of Medical Microbiology, Aberdeen Royal Infirmary, Foresterhill, Aberdeen AB9 2ZD

\begin{abstract}
Verocytotoxin-producing Escherichia coli 0157 (0157 VTEC) has become well recognised as an important enteric pathogen. The number of organisms present in environmental and clinical samples may be low and efforts have been made to increase the sensitivity of 0157 VTEC detection. Immunomagnetic separation (IMS) has been shown to improve 0157 VTEC detection in bovine faeces and food samples. A milkborne outbreak of 0157 VTEC infection allowed us to compare the isolation rates from human faeces by IMS, direct faecal culture on sorbitol-MacConkey agar and a PCR test for verotoxin gene carriage. Of 142 faecal samples examined, 20 were positive on both direct culture and IMS and a further 13 on IMS alone. Therefore, IMS increased the detection rate of individual cases of 0157 VTEC infection and also compared well with PCR. We recommend IMS for use in routine diagnostic laboratories where a more sensitive method than direct faecal culture is required for 0157 VTEC isolation.
\end{abstract}

\section{Introduction}

Verocytotoxin (VT)-producing Escherichia coli $\mathrm{O} 157$ (O157 VTEC) has become widely recognised as an important enteric pathogen and a major cause of haemorrhagic colitis and the haemolytic uraemic syndrome [1-3]. Many laboratories culture 0157 VTEC from clinical and environmental samples with sorbitol-MacConkey (SMAC) agar. O157 VTEC is recognised by the failure of most strains to ferment $\mathrm{D}$ sorbitol within $24 \mathrm{~h} \mathrm{[4]} \mathrm{followed} \mathrm{by} \mathrm{confirmation} \mathrm{of}$ O157 serogroup by latex agglutination [5, 6], identification as $E$. coli by biochemical testing and VT detection by either a Vero cell assay [7] or colony hybridisation with DNA probes specific for VT genes [8].

The numbers of 0157 VTEC present in environmental samples, food and human faeces may be low and efforts have been made to increase the sensitivity of detection of this organism [9]. Improvements in sensitivity have been achieved by the modification of SMAC agar by the addition of cefixime and tellurite for higher selectivity [10] and of rhamnose, which leads to better discrimination from non-0157 $E$.

Received 20 March 1995; revised version accepted 22 Aug. 1995. coli [11]. Selective liquid enrichment media for the isolation of 0157 VTEC have also been developed, but with limited success to date [9].

The disadvantage of these cultural methods is that they do not differentiate between toxigenic and nontoxigenic strains of E. coli $\mathrm{O} 157$ and toxin has to be detected subsequently in the isolate. These methods also fail to detect toxigenic $E$. coli of serogroups other than 0157. Techniques are available for VT detection in faeces, such as cell culture assay [12], although this may detect faecal cytotoxins other than VT because there is no VT antitoxin that will confirm the presence of VT by neutralisation [9]. The various VT ELISA tests are not sufficiently sensitive for this purpose [9]. VT gene probes have been used to detect VT gene DNA sequences in E. coli cultures [9] and PCR for VT genes is now used in primary faecal cultures [13].

Although there has been some success with the above methods, there remains the need for a simple, cheap and reliable procedure to increase the sensitivity of 0157 VTEC detection in human faeces and in environmental samples such as food and water. Immunomagnetic separation (IMS) has been shown to improve $E$. coli $\mathrm{O} 157$ isolation rates from bovine faeces [14], milk [15] and artificially inoculated food $[16-18]$ when combined with the use of SMAC agar $[17,18]$ and SMAC agar with cefixime [14-16]. 
A large milk-borne outbreak of O157 VTEC infection [19] provided the opportunity to compare the rate of detection of 0157 VTEC in human faeces by IMS with the rates obtained by direct culture on SMAC agar and by PCR for VT genes in primary faecal cultures.

\section{Materials and methods}

A total of 142 faecal samples from 90 patients with suspected VTEC infection was collected. A single outbreak of phage type 2 VTEC infection [19] provided 126 samples from 79 patients and the other 16 samples were derived from 11 patients involved in smaller outbreaks of infection with phage types 2 and 28 . The date of collection of the faeces was available for 122 samples. Nineteen patients provided more than one sample each (range 2-6 samples) totalling 57 samples. Nine of these patients had more than one sample taken in any one day. One hundred and twenty samples had been forwarded to us by other laboratories where they had initially been tested for VTEC by direct culture on SMAC agar and 29 had been found to be positive. The remaining 22 samples were tested for the first time in our laboratory.

All samples were stored at $4^{\circ} \mathrm{C}$ before analysis by direct culture on SMAC agar, simple enrichment and IMS as described below.

\section{Direct culture}

SMAC agar plates containing D-sorbitol (Oxoid) $1 \%$ were inoculated directly with a pea-sized sample of faeces with a standard cotton-wool swab and were incubated in air at $37^{\circ} \mathrm{C}$ for $18-24 \mathrm{~h}$.

\section{Enrichment}

An inoculum of faeces similar to that above was added to $10 \mathrm{ml}$ of buffered peptone water (Oxoid) and incubated at $37^{\circ} \mathrm{C}$ for $6 \mathrm{~h}$. This enrichment step constituted the first stage of the IMS procedure. To ensure that a subsequent positive result was due to the IMS and not to the enrichment, a standard loopful of the 6-h broth was streaked on SMAC agar and incubated as for direct culture.

\section{Immunomagnetic separation}

After incubation for $6 \mathrm{~h}, 1 \mathrm{ml}$ of the broth culture was added to $20 \mu \mathrm{l}$ of magnetic bead suspension (Dynabeads anti- $E$. coli O157; Dynal, Oslo) in a $1.5-\mathrm{ml}$ sterile Eppendorf tube and the separation was performed as described previously [14]. The final bead pellet was resuspended in $100 \mu \mathrm{l}$ of PBS-Tween 20, $50 \mu \mathrm{l}$ of which was used to inoculate a third SMAC agar plate, which was incubated in air at $37^{\circ} \mathrm{C}$ for 18 $24 \mathrm{~h}$.

\section{Identification of isolates}

After incubation, all plates were inspected for pale colonies that did not ferment sorbitol. One colony from each pale colony type was serotested with an E. coli O157 latex agglutination kit (Oxoid). Latex positive cultures were confirmed as E. coli by use of API 20E strips (bioMérieux, France). Identification and verotoxin gene carriage were confirmed and E. coli 0157 isolates were phage-typed at the Scottish $E$. coli 0157 Reference Laboratory in Aberdeen.

\section{$V T$ gene PCR}

Where possible, all faecal samples, irrespective of $E$. coli 0157 culture results, were forwarded to the Aberdeen reference laboratory for detection of VT genes by PCR. The PCR was performed after IMS in all cases within 1-4 weeks. Faecal samples were returned to storage at $4^{\circ} \mathrm{C}$ while awaiting PCR. A total of 140 samples was tested with a PCR for the genes encoding verotoxins 1 and 2 as described previously [20]. The amplification products were not checked by hybridisation with specific DNA probes.

\section{Results}

\section{IMS compared with direct culture}

Of the 142 faecal samples examined, O157 VTEC was isolated from 33 , representing 25 patients. Twenty samples (13 patients) were positive on both direct culture and IMS and 13 samples (12 patients) were positive on IMS only. Six new cases of O157 VTEC infection were detected by IMS. No sample was positive on direct culture but negative on IMS (Table 1).

\section{Results of direct plating of enrichment broth compared with IMS}

Of the 13 samples that were negative on direct culture and positive after IMS, only two were positive on direct plating after simple enrichment in peptone water. Twenty samples were positive on both direct culture and IMS, of which 19 were positive after enrichment (Table 2).

Table 1. Comparison of E. coli 0157 detection by direct culture and IMS

\begin{tabular}{lcccc}
\hline E. coli O157 & isolated by & & $\begin{array}{c}\text { Number of } \\
\text { samples }\end{array}$ & $\begin{array}{c}\text { Number of } \\
\text { patients }\end{array}$ \\
\hline direct culture & IMS & & 0 & 0 \\
\hline+ & - & 20 & 13 \\
+ & + & 13 & 12 \\
- & + & 109 & 65 \\
- & - & 142 & 90 \\
Total & & & \\
\hline
\end{tabular}


Table 2. Results after enrichment compared with results of direct culture and IMS for $E$. coli $\mathrm{O} 157$ detection

\begin{tabular}{lccc}
\hline $\begin{array}{l}\text { Direct } \\
\text { culture }\end{array}$ & $\begin{array}{c}\text { Enrichment } \\
\text { result }\end{array}$ & $\begin{array}{c}\text { IMS } \\
\text { result }\end{array}$ & $\begin{array}{c}\text { Number of } \\
\text { samples }\end{array}$ \\
\hline \multirow{3}{*}{ Negative } & + & + & 2 \\
& - & + & 11 \\
& + & - & 0 \\
Positive & + & + & 19 \\
& - & + & 1 \\
\hline
\end{tabular}

Results obtained on samples known previously to be positive before entry into the study

The faecal samples studied were of various ages before simultaneous performance of direct culture and IMS. Some of the samples that were known to have been positive originally on direct culture proved subsequently to be negative on both direct culture and IMS, whereas others were positive on IMS only. The date of collection of the faeces was available for 35 such samples and the mean age at the time of testing was calculated. Fourteen samples with a mean age of 12.78 days (range 3-31 days) remained positive on direct culture and IMS. Seven previously positive samples, now positive on IMS only, had a mean age of 29.14 days (range 20-38 days). Fourteen samples with a mean age of 33.64 days (range 26-66 days) were now negative on IMS as well as on direct culture (Table 3).

A $t$ test was used to compare these means. The samples that were positive on IMS alone were significantly older than those which remained positive on direct culture $(p<0.001)$. There was no significant difference in the ages of the samples that were IMS positive alone and those that were completely negative $(0.1<\mathrm{p}<0.5)$.

\section{Verotoxin gene PCR compared with IMS}

One hundred and forty samples were examined by PCR. The remaining two samples in the study were of insufficient volume for further examination. The PCR was performed on DNA from primary faecal cultures. No growth was obtained from 43 samples although six of these had been positive on IMS.

PCR for VT2 was negative on 79 samples, 15 of which had been positive on IMS, whereas 16 were

Table 3. Mean ages of previously positive samples with results of subsequent direct culture and IMS for $E$. coli O157 detection

\begin{tabular}{lccc}
\hline $\begin{array}{l}\text { Direct } \\
\text { culture }\end{array}$ & IMS & $\begin{array}{c}\text { Number of } \\
\text { samples }\end{array}$ & $\begin{array}{c}\text { Mean age of } \\
\text { sample (days) }\end{array}$ \\
\hline+ & - & 0 & 0 \\
+ & + & 14 & 12.78 \\
- & + & 7 & 29.14 \\
- & - & 14 & 33.64 \\
\hline
\end{tabular}

Table 4. Results of VT2 gene PCR compared with $E$. coli $\mathrm{O} 157$ detection by IMS

\begin{tabular}{lcc}
\hline VT2 gene PCR result & IMS result & Number of samples \\
\hline+ & - & 4 \\
+ & + & 12 \\
- & + & 15 \\
- & - & 64 \\
No growth & - & 37 \\
No growth & + & 6 \\
\hline
\end{tabular}

VT2 PCR positive, four of which had been negative on IMS (Table 4). Of the four samples that were VT2 PCR positive and IMS negative, two were from a single patient who had been consistently culture negative. The others were from two patients, previously culture positive at the laboratory of origin, and now negative on both direct culture and IMS in this study. Two samples were VT1 PCR positive. These were from one patient and were consistently negative for 0157 VTEC on both direct culture and IMS. Repeated attempts were made to isolate PCR positive colonies from all four samples that had been consistently culture negative and PCR positive but no single PCR positive colonies could be identified.

\section{Discussion}

This study has demonstrated that IMS was more sensitive than direct faecal culture on SMAC agar for the isolation of 0157 VTEC, increasing the number of positive samples from 20 to 33 (an increase of $65 \%$ ). Overall, six new cases of infection were detected by IMS. This effect would appear to have been due to the IMS procedure itself and not a result of simple enrichment in buffered peptone water before IMS.

Many of the samples tested were forwarded to us by other laboratories investigating the outbreak [19] and some were known to have been positive on direct culture for 0157 VTEC before a repeat direct culture at the same time as IMS. Some of these previously positive samples were found to be positive on IMS only or were completely negative. Those in the latter two categories were significantly older than those remaining positive on direct culture, indicating that as the number of viable organisms declined with storage of faeces, IMS was more able than direct culture to detect the small number present. It has been shown [21] that the O157 VTEC detection rate in faeces declines rapidly after the onset of diarrhoeal illness and IMS may have a role in extending the time during which the organism can be isolated from patients with suspected infection. This has important diagnostic implications in cases of haemolytic uraemic syndrome when the patient may present late in the diarrhoeal phase of the illness with very small numbers of 0157 VTEC organisms in the faeces, the detection of which could be missed by direct culture on SMAC agar alone. In cases of haemolytic uraemic syndrome, 
serological diagnosis of O157 VTEC infection may be useful in establishing the aetiology but may not be of adequate sensitivity. Results by this method are often delayed because this test is currently only available from reference laboratories.

IMS compared favourably with the VT gene PCR, and 15 samples were IMS positive and PCR negative. However, in most cases there was a considerable delay before PCR was performed. Since the PCR was performed on primary faecal cultures, the results may not be comparable on account of the possible loss of viable organisms. Simultaneous IMS and PCR would allow a truer comparison.

Four samples were VT2 PCR positive but IMS negative. Two of these had previously been positive on direct culture before negative results on simultaneous direct culture and IMS and this may indicate that PCR was more sensitive than IMS. The other two samples were from one patient, from whose faeces 0157 VTEC had not been isolated at any stage. A further two samples, both from another patient, were VT1 PCR positive, although O157 VTEC had also not been isolated from these samples. Carriage of the VT1 gene was confirmed by DNA sequencing (unpublished observation). This could also be an indication that PCR was more sensitive than IMS but the occurrence of PCR positive, IMS negative samples might also be explained by the presence of non-O157 VTEC or verotoxigenic organisms other than $E$. coli.

In summary, IMS has been shown to be more sensitive than direct culture for the detection of 0157 VTEC. Its sensitivity may be increased further by the use of SMAC agar containing cefixime and tellurite as recommended by the manufacturer of the immunomagnetic beads (Dynal, Oslo). As this study was part of the investigation of an outbreak of O157 VTEC infection, it was felt inappropriate to change from our standard use of non-selective SMAC agar. The VT gene PCR may be even more sensitive than IMS, although further work is needed to establish this point. However, PCR is likely to be valuable in detecting and evaluating the significance of organisms other than E. coli 0157 that possess the VT1 and VT2 genes. PCR, at present, requires more expertise and equipment than does IMS and cannot at this stage be recommended as a routine diagnostic method. IMS is a simple, cheap procedure and is better suited to the diagnostic laboratory. Unlike PCR, IMS leads to the isolation of an organism on which toxin and phage typing can be performed and will, therefore, contribute to epidemiological studies of O157 VTEC infection.

We thank Lesley Allison and Anne Stirrat of the Scottish E. coli O157 Reference Laboratory in Aberdeen for their assistance.

\section{References}

1. Riley LW, Rimis RS, Helgerson SD et al. Hemorrhagic colitis associated with a rare Escherichia coli serotype. $N$ Engl J Med 1983; 308: 681-685.

2. Karmali MA, Petric M, Steele BT, Lim C. Sporadic cases of haemolytic uraemic syndrome associated with faecal cytotoxin and cytotoxin-producing Escherichia coli in stools. Lancet 1983; 1: 619-620.

3. Gross RJ. Escherichia coli diarrhoea. In: Smith GR, Easmon CSF (eds) Topley and Wilson's Principles of bacteriology, virology and immunity, 8th edn. London: Hodder and Stoughton. 1990: 469-487.

4. March SB, Ratnam S. Sorbitol MacConkey medium for the detection of Escherichia coli O157:H7 associated with haemorrhagic colitis. J Clin Microbiol 1986; 23: 869-872.

5. Chapman PA. Evaluation of commercial latex slide test for identifying Escherichia coli 0157. J Clin Pathol 1989; 42: 1109-1110.

6. March SB, Ratnam S. Latex agglutination test for the detection of Escherichia coli serotype 0157. J Clin Microbiol 1989; 27: 1675-1677.

7. Konowalchuk J, Spiers JI, Stavric S. Vero response to a cytotoxin of Escherichia coli. Infect Immun 1977; 18: 775779.

8. Scotland SM, Rowe B, Smith HR, Willshaw GA, Gross RJ. Verocytotoxin-producing strains of Escherichia coli from children with haemolytic uraemic syndrome and their detection by specific DNA probes. $J$ Med Microbiol 1988; 25: 237-243.

9. Chapman PA. Isolation, identification and typing of verocytotoxin-producing Escherichia coli O157. PHLS Microbiology Digest 1994; 11: 13-17.

10. Chapman PA, Siddons CA, Zadik PM, Jewes L. An improved selective medium for the isolation of Escherichia coli 0157. J Med Microbiol 1991; 35: 107-110.

11. Zadik PM, Chapman PA, Siddons CA. Use of tellurite for the selection of verocytotoxigenic Escherichia coli 0157. J Med Microbiol 1993; 39: 155-158.

12. Ritchie M, Partington S, Jessop J, Kelly MT. Comparison of a direct shiga-like toxin assay and sorbitol MacConkey agar culture for laboratory diagnosis of enterohaemorrhagic Escherichia coli infection. J Clin Microbiol 1992; 30: 461-464.

13. Paton AW, Paton JC, Goldwater PN, Manning PA. Direct detection of Escherichia coli shiga-like toxin genes in primary faecal cultures by polymerase chain reaction. J Clin Microbiol 1993; 31: 3063-3067.

14. Chapman PA, Wright DJ, Siddons CA. A comparison of immunomagnetic separation and direct culture for the isolation of verocytotoxin-producing Escherichia coli 0157 from bovine faeces. J Med Microbiol 1994; 40: 424-427.

15. Chapman PA, Wright DJ, Higgins SR. Untreated milk as a source of verotoxigenic Escherichia coli O157. Vet Rec 1993; 133: $171-172$.

16. Wright DJ, Chapman PA, Siddons CA. Immunomagnetic separation as a sensitive method for isolating Escherichia coli 0157 from food samples. Epidemiol Infect 1994; 113: 31-39.

17. Okrend AJG, Rose BE, Lattuada CP. Isolation of Escherichia coli 0157:H7 using O157 specific antibody coated magnetic beads. J Food Protect 1992; 55: 214-217.

18. Mortlock S. Recovery of Escherichia coli 0157:H7 from mixed suspensions: evaluation and comparison of pre-coated immunomagnetic beads and direct plating. Br J Biomed Sci 1994; 51: 207-214.

19. Upton P, Coia JE. Outbreak of Escherichia coli 0157 infection associated with a pasteurised milk supply. Lancet 1994; 344: 1015.

20. Pollard DR, Johnson WM, Lior H, Tyler SD, Rozee KR. Rapid and specific detection of verotoxin genes in Escherichia coli by the polymerase chain reaction. J Clin Microbiol 1990; 28: 540-545.

21. Tarr PI, Neill MA, Clausen CR, Watkins SL, Christie DL, Hickman RO. Escherichia coli $\mathrm{O} 157: \mathrm{H} 7$ and the haemolytic uraemic syndrome: importance of early cultures in establishing the etiology. $J$ Infect Dis 1990; 162: 553-556. 